\title{
Análisis prosódico del par adverbial sólo-solamente en el registro oral-informal del español de Monterrey"
}

\author{
LORENA Y. MEDINA GÓMEZ** \\ lorenamedinagomez@gmail.com
}

EVA PATRICIA VELÁSQUEZ UPEGUI evapvelasquez@gmail.com

Forma de citar este artículo: Medina Gómez, L.Y., \& Velásquez Upegui, E.P. (2016). Análisis prosódico del par adverbial sólosolamente en el registro oral-informal del español de Monterrey. Cuadernos de Lingüística Hispánica, (28), 41-67. doi: http:// dx.doi.org/10.19053/0121053X.4908

\footnotetext{
* Artículo de Investigación. El presente trabajo forma parte del proyecto de investigación "Análisis del par adverbial sólo-solamente" en el registro oral informal del español de México", aprobado en Consejo Académico y registrado ante el Departamento de Investigación y Posgrado de la Facultad de Lenguas y Letras de la Universidad Autónoma de Querétaro, UAQ.

** Estudiante Doctorado Lingüística de tiempo completo con beca CONACYT. Tema de investigación para titulación: Análisis descriptivo del par adverbial sólo-solamente en el español oral de México.

*** Doctora en Linguística. El Colegio de México. Profesora-Investigadora. Universidad Autónoma de Querétaro.
} 


\title{
Resumen
}

A pesar de la extensa bibliografía especializada que existe en el estudio de los adverbios, hay un escaso número de investigaciones dedicadas a observar su realización prosódica. En este análisis se describen los contornos melódicos que presenta el par adverbial sólo-solamente y se determina si dichos contornos son sistemáticos cuando estos elementos promueven un valor semántico o un valor pragmático. Para este estudio, se utilizan 88 ejemplos de registro oral informal que forman parte del Corpus del Habla de Monterrey. Todos los casos se analizan bajo los parámetros del Modelo Métrico Autosegmental (AM) y el sistema de transcripción Sp-ToBI. Los resultados muestran que la realización prosódica del par adverbial presenta configuraciones vinculadas al contenido pragmático, pero no se trata de categorías discretas, dado que hay casos en los que se prescinde de estrategias prosódicas y se mantienen estrategias discursivas como el contexto y el contenido léxico.

Palabras clave: adverbios discursivos, prosodia, semántica, pragmática, atenuación, intensificación.

\section{Prosodic analysis of the adverbial pair: "sólo-solamente" [just-only] in the Spanish oral-informal register of the city of Monterrey.}

\begin{abstract}
Despite of the existence of a large, specialized literature regarding to the study of adverbs, there is still a scarce number of investigations about their prosodic realization. In this article, the melodic contours of the adverbial pair "sólo-solamente" [just-only] are described. Also, it is determined if the mentioned contours are systematic when they foster a semantic or pragmatic value. For this study, 88 examples of the oral-informal register belonging to the Corpus de Habla de Monterrey [Speech Corpus of Monterrey] were used. All cases were analyzed under the criteria of the Metric and Autosegmental Model (AM) and the transcription system Sp-ToBI. The results show that the prosodic realization of the adverbial pair presents configurations linked to the pragmatic content, but this is not a matter of discrete categories, because there are some cases in which prosodic strategies are absent and discursive strategies, such as context and lexical content, are maintained.
\end{abstract}

Key words: Discursive adverbs, prosody, semantic, pragmatic, attenuation, intensification. 


\section{Analyse prosodique du pair adverbial sólo-solamente (seulement) dans le registre oral-informel de l'espagnol de Monterrey}

\section{Résumé}

Malgré la vaste bibliographie spécialisée existante sur l'étude des adverbes, il y a peu de recherches dédiées à observer leur réalisation prosodique. Dans cette analyse, on décrit les contours mélodiques qi présente le pair adverbial sólo-solamente et on détermine si ces contours-là sont systémiques quand ces éléments promeuvent une valeur sémantique ou une valeur pragamatique. Pour cette étude, on utilise 88 exemples du registre oral informel qui font partie du Corpus du Parler de Monterrey. Tous les cas s'analysent sous les paramètres du Modèle Métrique Auto-segmental (AM) et le système de transcription SpToBI. Les résultats montrent que la réalisation prosodique du pair adverbial présente des configurations liées au contenu pragmatique, mais il s'agit de catégories discrètes, étant donné qu'il y a des cas dans lesquels on se passe de stratégies prosodiques et on maintient des stratégies discursives comme le contexte et le contenu lexique.

Mots clés: adverbes discursives, prosodie, sémantique, pragmatique, atténuation, intensification.

\section{Análise prosódica do par adverbial só-somente no registro oral-informal do espanhol de Monterrey}

\section{Resumo}

Apesar da extensa bibliografia especializada que existe no estudo dos advérbios, há um escasso número de pesquisas dedicadas a observar sua realização prosódica. Nesta análise se descrevem os contornos melódicos que apresenta o par adverbial só-somente e se determina se tais contornos são sistemáticos quando estes elementos promovem um valor semântico ou um valor pragmático. Para este estudo, se utilizam 88 exemplos de registro oral informal que formam parte do Corpus da Fala de Monterrey. Todos os casos se analisam sob os parâmetros do Modelo Métrico Autossegmental (AM) e o sistema de transcrição Sp-ToBI. Os resultados mostram que a realização prosódica do par adverbial apresenta configurações vinculadas ao conteúdo pragmático, mas não se trata de categorias discretas, já que tem casos nos quais se prescinde de estratégias prosódicas e se mantêm estratégias discursivas como o contexto e o conteúdo léxico.

Palavras chave: advérbios discursivos, prosódia, semântica, pragmática, atenuação, intensificação. 
"Agradecemos al Dr. Eduardo P. Velázquez Patiño y a la Dra. Luisa Josefina Alarcón Neve por su valiosa ayuda y retroalimentación."

\section{Introducción}

El adverbio, en general, ha sido objeto de múltiples estudios, en ellos se ha atendido a problemas morfológicos (Egea, 1979; Kaul de Marlangeon, 2002), semánticos, sintácticos y funcionales (Arjona, 1986; Vigueras, 1983); sin embargo, hay pocos estudios de tipo prosódico que dan cuenta de este elemento gramatical (Mora, 2011) y, hasta el momento, no se ha encontrado algún análisis que describa al adverbio en par, es decir, al adjetivo adverbializado que se ejemplifica en (1) (De Mello, 1992; Hummel, 2002) y al adverbio terminado en el sufijo -mente como se ve en (2) (Kovacci, 2000; Kaul de Marlangeon, 2002). ${ }^{1}$

1. La niña corre rápido.

2. La niña corre rápidamente.

En el registro oral del español de Monterrey, el par adverbial sólo-solamente es de uso frecuente. Los hablantes emplean estos elementos discursivos para enfatizar, delimitar, seleccionar y focalizar la información. Asimismo, se observa que, además, este par de elementos matiza lo dicho, es decir, atenúan o intensifican la información comunicada.

Cuando el hablante utiliza el par adverbial puede modificar el contorno prosódico, con ello busca que su interlocutor comparta el valor que le otorga a la enunciación. Por ello, para nosotras es de sumo interés reconocer las estrategias prosódicas utilizadas por los hablantes para evidenciar el valor pragmático de sólo-solamente en el discurso.

La hipótesis que orienta esta investigación es que el hablante se vale de estrategias prosódicas como la altura tonal para comunicar valores semánticos y pragmáticos. Se ha documentado ampliamente que esta estrategia da relevancia o prominencia entonativa al enunciado (cfr. Prieto, 2003, p. 13) y, además, marca la información central del mensaje (Face, 2002, p. 42).

1 En este trabajo se identificará al adjetivo adverbializado como adverbio corto y al adverbio con terminación -mente como adverbio largo. 
A pesar de la recurrencia en el uso de los adverbios en el habla coloquial, existe un escaso número de investigaciones que estudian su realización prosódica, de modo que el objetivo general de este análisis es describir los contornos melódicos que presenta el par adverbial sólo-solamente y determinar si dichos contornos son sistemáticos cuando estos elementos promueven un valor semántico o pragmático. ${ }^{2}$

A continuación se presenta el marco teórico seguido por la descripción metodológica. Posteriormente, se reporta el análisis de los datos y, por último, se presentan las conclusiones derivadas de esta investigación.

\section{Marco teórico}

\section{Nociones semánticas, pragmáticas y prosódicas del par adverbial sólo- solamente}

Los hablantes que participaron en el Corpus El Habla de Monterrey utilizaron 122 construcciones lingüísticas en donde apareció alguna de las dos formas adverbiales, sólosolamente. En cuanto a su valor semántico, estos elementos se emplean para denotar exclusión, limite, restricción (Martínez, 2006, p. 1438; RAE \& ASALE, 2010, p. 764; Ferrari, Giammatteo \& Albano, 2011, p. 30; Hummel, 2012, p.143) o unicidad (Seco, 2002, p. 417; Lara, 2011, p.1524) como en los ejemplos (3 y 4$){ }^{3}$

3. E: ¿y qué fue lo que te hizo / a- acercarte así / de esa manera / a dios?

I: no pos / sólo dios me puso en mi sentir / porque pues / nunca nunca fui drogadicto

E: jórale! (CHDM)

Fuente: CHDM, hombre, generación 1, nivel de instrucción 1.

4. E: ¿qué funciones tiene su celular? / ya ve que ahorita hay muchos que con camarita / video

I: sí / yo de esos no / no me gustan

E: ¿solamente lo más básico? (CHDM)

Fuente: CHDM, mujer, generación 1, nivel de instrucción 2.

En relación con la función discursiva, los adverbios sólo y solamente remiten a la estructura de la información, puesto que son caracterizados como operadores de foco,

2 Se consideraron aspectos prosódicos como el acento, la duración silábica y la entonación; de estos, el último resultó ser significativo en la diferenciación del par adverbial. Por esta razón, el análisis se enfocó en la curva melódica.

3 Los ejemplos se conservan tal y como aparecen en el corpus porque pensamos que las repeticiones, apócopes e, incluso, en algunas ocasiones, falsos inicios revelan información contextual. 
debido a que acompañan a otro elemento al que dan prominencia "The adverb only, [...] is called a focus adverb, because it requires a focus constituent in its environment" (Hoeksema \& Zwarts, 1991, p. 52). ${ }^{4}$

A este elemento prominente se le ha etiquetado como foco y, sintácticamente, se ubica bajo el dominio o alcance del operador. ${ }^{5}$ Los focos se han clasificado de manera convencional en amplios y estrechos; ${ }^{6}$ los primeros se emplean cuando toda la información del enunciado está focalizada y se identifica como información nueva, ejemplificado en (5) (cfr. Gutiérrez Bravo, 2008, p. 377). En contraste, los focos estrechos identifican y resaltan a una entidad específica de entre un conjunto de posibles alternativas como en (6) (cfr. Gutiérrez Bravo, 2008, p. 376).

5. ¿Qué pasó?

La enfermera salvó al paciente (Gutiérrez Bravo, 2008, p. 381)

(Toda la cláusula es información nueva)

6. Sólo Pedro se rindió. (Gutiérrez Bravo, 2008, p.378)

(Y nadie más. El foco contrastivo es Pedro)

Por otro lado, los focos estrechos pueden ser de tipo contrastivo, en tales casos «[... tienen la propiedad de aparecer con un "operador de foco", que típicamente es un elemento adverbial cuya función semántica implica exclusividad o exhaustividad» (Gutiérrez Bravo, 2008, p. 378).

Asimismo, dentro de la pragmática se observa que este par adverbial se usa estratégicamente por el hablante para revelar su actitud o juicio de valor con respecto a lo enunciado (Lope Blanch, 1977, p. 313; Di Tullio, 2010, p. 141; RAE, 2010, p. 593; Hummel, 2012, p.145). En el ejemplo (7), en opinión del interlocutor, el número de horas es insuficiente.

7. Beatriz sólo trabaja cuarenta horas semanales.

(En opinión de emisor, ese número de horas es insuficiente)

Así, la carga pragmática de estos elementos dependerá, por un lado, del contexto en el que surja la interacción comunicativa entre los interlocutores y, por el otro, de la

4 "El adverbio sólo, [...] es llamado adverbio focal, porque requiere de un constituyente focal en su contexto" (Hoeksema \& Zwarts, 1991, p. 52) (Traducción nuestra).

5 Se identifica a los focos con letra cursiva y negrilla.

6 Esta terminología es la que adoptaremos en este trabajo. Estos focos también se conocen como informativos o presentacionales y contrastivos (Face, 2002; Gutiérrez Bravo, 2008). 
prosodia; por lo tanto, la interpretación estará también condicionada por la idiosincrasia y cultura de los hablantes como lo afirma Prieto (2003):

En lenguas entonativas, como las lenguas románicas, las variaciones melódicas no se usan para distinguir palabras [...] sino para manifestar una serie de sentidos pragmáticos que afectan generalmente a todo el enunciado. El carácter lingüístico de la entonación se pone de manifiesto en el hecho de que los patrones melódicos son modelos definidos que se usan para expresar las intenciones comunicativas del hablante. (p. 13).

Como se comentó anteriormente, no se ha encontrado hasta el momento algún análisis que dé cuenta del comportamiento prosódico de los adverbios en par. Mora (2011) presenta un análisis de oraciones simples que pertenecen a entrevistas espontáneas, su interés es observar la correlación entre prosodia y los adverbios terminados en -mente. El autor concluye que hay variabilidad en el fraseo melódico y en la configuración tonal de los adverbios según su pesantez, es decir, de acuerdo con el número de sílabas que constituyen al adverbio. Asimismo, autores como Zubizarreta (2000), Albelda (2002), Face (2002), Hualde (2003) y Prieto (2003) mencionan la relevancia del análisis prosódico en relación con aspectos pragmáticos, aunque no se dedican de manera exclusiva a la descripción del adverbio. Por esta razón, es necesario un análisis que muestre los contornos melódicos de estos operadores de foco, y así determinar si los movimientos melódicos se correlacionan con la información semántica y pragmática que portan en determinado contexto.

\section{Metodología}

\subsection{Corpus}

Los datos analizados son parte del Corpus El habla de Monterrey-PRESEEA ${ }^{7}$ (CHDM). El CHDM representa el habla oral de una de las ciudades más importantes de la República Mexicana. Este corpus se recopila siguiendo la metodología del proyecto PRESEEA que toma como base el enfoque sociolingüístico para crear un corpus equivalente en todos los dialectos del español de América y España. Los materiales tienen amplia variedad discursiva, ya que incluyen fragmentos narrativos, argumentativos y descriptivos de naturaleza espontánea.

El CHDM consta de 108 entrevistas; número suficiente según la representatividad de la muestra $\geq 0,025$ (cfr. Rodríguez, Flores \& Pérez, 2000; 2003; 2009; 2012). Las

7 El CHDM es parte de un estudio mayor llamado: Proyecto de Estudios Sociolingüísticos del Español de España y América (PRESEEA), su objetivo fue hacer una recopilación de variantes orales del español de diferentes ciudades de España y del continente americano (cfr. Rodríguez, Flores \& Pérez, 2012). 
entrevistas se distribuyen de acuerdo con tres variables sociales: género, edad y grado de instrucción. ${ }^{8}$ Con el fin de obtener una producción espontánea, todas las entrevistas fueron realizadas en contextos naturales, los informantes se encontraban en su casa, trabajo 0 escuela. Las entrevistas fluctúan entre 45 minutos y dos horas de grabación. Los temas de los que se hablan tienen que ver con la vida diaria como niñez, juegos, problemas de trabajo, estudios, estrés, dinero, relaciones personales, entre otros.

\subsection{Recopilación de datos}

En total, se encontraron 122 ejemplos que contenían uno u otro elemento del par adverbial, sólo-solamente, de estos se descartaron 34 casos, debido a factores técnicos como el solapamiento en el discurso de los participantes, las transcripciones confusas y la calidad deficiente del audio. Al final, se analizaron 88 casos, 45 adverbios cortos y 43 largos.

Una vez que se obtuvo la muestra, se clasificaron los datos de acuerdo con consideraciones prosódicas, semánticas y pragmáticas. En lo que respecta al análisis prosódico, en primera instancia, se extrajeron los fragmentos discursivos que contenían los adverbios en cada una de las entrevistas con ayuda del programa Audacity (en línea); después, se analizaron las representaciones acústicas del enunciado a través del programa Praat versión 5.3.42 (Boersma \& Weenink, 2013). Posteriormente, se segmentaron y se etiquetaron los datos de acuerdo con el Modelo Métrico-Autosegmental (AM) ${ }^{9}$ (Hualde, 2003) y al sistema de transcripción Sp-ToBI (Spanish-Tones and Break Indices) (Sosa, 2003; Estebas \& Prieto, 2008).

El modelo AM proporciona un andamiaje teórico para analizar la prosodia en una lengua. Este enfoque considera la entonación como un nivel autónomo que puede ser representado fonológicamente y, al mismo tiempo, dependiente de la estructura métrica de las palabras y frases. "[...] El objetivo del modelo es la identificación de los elementos contrastivos del sistema entonativo, cuya combinación produce los contornos melódicos que encontramos en los enunciados posibles de la lengua" (Hualde, 2003, p. 155).

8 En cuanto al género, en las entrevistas participan igual número de hombres que de mujeres, 54 de cada uno. La variable edad se divide en tres subgrupos, identificados como generación 1, 2 y 3. La generación 1 involucra participantes de 20 a 34 años; la generación 2, de 35 a 54; y la generación 3, de 55 años en adelante. Por último, se halla la variable grado de instrucción, de la cual se desprenden tres subgrupos, nivel 1,2 y 3 . En el nivel uno se ubican a aquellas personas que tengan de 0 a 8 años de instrucción formal, esto es, analfabetos hasta secundaria incompleta; el nivel 2, a aquellos que hayan tenido de 9 a 14 años de instrucción, es decir, personas que cuentan con certificado de secundaria y licenciatura incompleta o carrera técnica; y el nivel 3, aquellas que tienen 15 años de instrucción formal como mínimo, personas con grado de licenciatura y más.

9 AM por las siglas en inglés. 
Dentro de esta perspectiva teórica existe una herramienta que permite representar los movimientos melódicos. Se trata del sistema de transcripción Sp-ToBI que está constituido por " $[\ldots]$ un conjunto de convenciones para la transcripción prosódica de múltiples variedades del español. Su propósito es ofrecer transcripciones sistemáticas de la prosodia de esta lengua [...]" (Sosa, 2003, p. 188).

Para este análisis, se han considerado las etiquetas para el español propuestas por Estebas \& Prieto (2008), las cuales hemos colocado en tres categorías con la finalidad de precisar las diferencias fonológicas. La primera corresponde a los tonos que consideramos sostenidos, que se caracterizan por una realización plana en la parte alta del campo tonal ${ }^{10}$ y se han etiquetado como $\mathrm{H}^{*}$. En la segunda categoría, agrupamos los tonos ascendentes que muestran una subida de la curva melódica que puede coincidir o no con la sílaba tónica, aquí se incluyen los bitonos $\mathrm{L}+\mathrm{H}^{*}$ y $\mathrm{L}+>\mathrm{H}^{*}$ y, por último, hemos considerado como tonos descendentes los movimientos que muestra una caída del tono representados con el bitono $\mathrm{H}+\mathrm{L}^{*}$. Para los tonos de juntura intermedia, hemos conservado las etiquetas propuestas por las autoras H-, M- o L- y para los tonos de juntura terminal utilizamos sólo dos $\mathrm{H} \%$ y $\mathrm{L} \%$.

Por último, se tomaron las medidas en semitonos de los contornos melódicos del operador de foco y del foco, con el fin de determinar el promedio de ascenso o descenso de la curva melódica y así contar con una descripción tanto cuantitativa como cualitativa. La diferencia entre un movimiento ascendente o descendente se estableció por medio de un umbral de 1.5 semitonos (st) (Pamies, Fernández, Martínez, Ortega \& Amorós, 2002).

Por otro lado, en cuanto al adverbio largo, es necesario aclarar que a pesar de la gran discusión existente entre si debe tomarse el acento del adjetivo base o el acento del afijo -mente como el principal, en este trabajo de investigación se toma el acento del adjetivo adverbializado por considerarlo el núcleo de compuesto (cfr. Kaul de Marlangeon 2002). ${ }^{11}$

Respecto del análisis semántico y pragmático, se determinó qué significado portaba cada uno de los ejemplos, con el fin de observar si la configuración melódica del operador y de su foco se correlacionan con el valor semántico y pragmático.

\footnotetext{
10 Esta medida se determinó a partir de la amplitud del campo tonal de cada enunciado y corresponde a los movimientos melódicos que se ubican arriba de la mitad del campo.

11 Además, en el adverbio largo solamente no resultaron frecuentes movimientos tonales asociados a las sílabas del sufijo.
} 


\section{Hallazgos}

\subsection{Análisis prosódico del par adverbial}

Los resultados muestran que el comportamiento prosódico de los 88 operadores de foco ${ }^{12}$ dibujan tres tendencias melódicas: alta-plana $\left(\mathrm{H}^{*}\right)$, ascendente $\left(\mathrm{L}+\mathrm{H}^{*}, \mathrm{~L}+>\mathrm{H}^{*}\right)$ y descendente $\left(\mathrm{H}+\mathrm{L}^{*}\right)$ (Véase Tabla 1). En la primera realización se encuentran 47 casos, de estos, 27 son adverbios largos y 20, adverbios cortos. Con la segunda curva melódica ocurrieron 28 operadores, 13 largos y 15 cortos. Por último, la representación descendente apareció en 13 ocasiones, 3 con solamente y 10 con sólo.

Tabla 1. Configuración prosódica general de los adverbios sólo - solamente

\begin{tabular}{|c|c|c|c|c|}
\hline \multicolumn{5}{|c|}{ Configuración general sólo - solamente } \\
\hline \multirow{2}{*}{ Alta-plana $\left(H^{*}\right)$} & \multirow{2}{*}{ F0 alta que inicia en la sílaba tónica y se mantiene } & \multirow{2}{*}{47} & corto & 20 \\
\hline & & & largo & 27 \\
\hline \multirow{2}{*}{$\begin{array}{l}\text { Ascendente } \\
\left(\mathrm{L}+\mathrm{H}^{*} \mathrm{y} \mathrm{L}+>\mathrm{H}^{*}\right)\end{array}$} & \multirow{2}{*}{$\begin{array}{l}\text { Ascenso de la F0 desde la sílaba tónica con o sin } \\
\text { prolongación en la sílaba post-tónica }\end{array}$} & \multirow{2}{*}{28} & corto & 15 \\
\hline & & & largo & 13 \\
\hline \multirow{2}{*}{$\begin{array}{l}\text { Descendente } \\
\left(\mathrm{H}+\mathrm{L}^{*}\right)\end{array}$} & \multirow{2}{*}{$\begin{array}{l}\text { Caída de la F0 desde la sílaba tónica hasta la sílaba } \\
\text { post-tónica }\end{array}$} & \multirow{2}{*}{13} & corto & 10 \\
\hline & & & largo & 3 \\
\hline & Total & 88 & Total & 88 \\
\hline
\end{tabular}

Como se observa, ambos adverbios presentan mayor ocurrencia con contornos melódicos $\mathrm{H}^{*}$; no obstante, el adverbio largo es más constante. El segundo tono en orden de frecuencia es $\mathrm{L}+\mathrm{H}^{*}$ y $\mathrm{L}+>\mathrm{H}^{* 13}$ con casi igual número de ejemplos, pero siendo el elemento corto más numeroso; y por último, con menos realizaciones, el tono descendente $\mathrm{H}+\mathrm{L}^{*}$, en donde la forma corta sigue siendo profusa. Al parecer, el adverbio largo se inclina por contornos $\mathrm{H}^{*}$, y el corto por contornos $\mathrm{L}+\mathrm{H}^{*}$ y $\mathrm{H}+\mathrm{L}^{*}$.

La realización $\mathrm{H}^{*}$ del operador de foco se muestra por encima de la línea media del enunciado, en promedio se ubica sobre 2.38 st. Esta configuración se presenta tanto en el adverbio como en el foco y sus complementos, como se observa en la Figura 1 y $2 .{ }^{14}$

Por lo regular, este tipo de patrón melódico aparece en enunciados de foco amplio, es decir, la proyección focal y prosódica se extiende a los diferentes constituyentes que componen el enunciado (Ver Tabla 2). El foco amplio constituye el 71 \% de esta realización.

12 Se utilizará indistintamente operador de foco o par adverbial para referir los elementos en análisis.

13 Con el fin de simplificar la lectura, a partir de este punto se colapsan los tonos ascendentes $\mathrm{L}+\mathrm{H}^{*}$ y $\mathrm{L}+>\mathrm{H}^{*}$ en la medida en que la diferencia en aparición no es significativa.

14 En la grada cinco, de todas las figuras, se ubica la medición en semitonos de los distintos contornos melódicos con el fin de ilustrar la altura. 
Figura 1. Sólo, sólo somos ella y yo

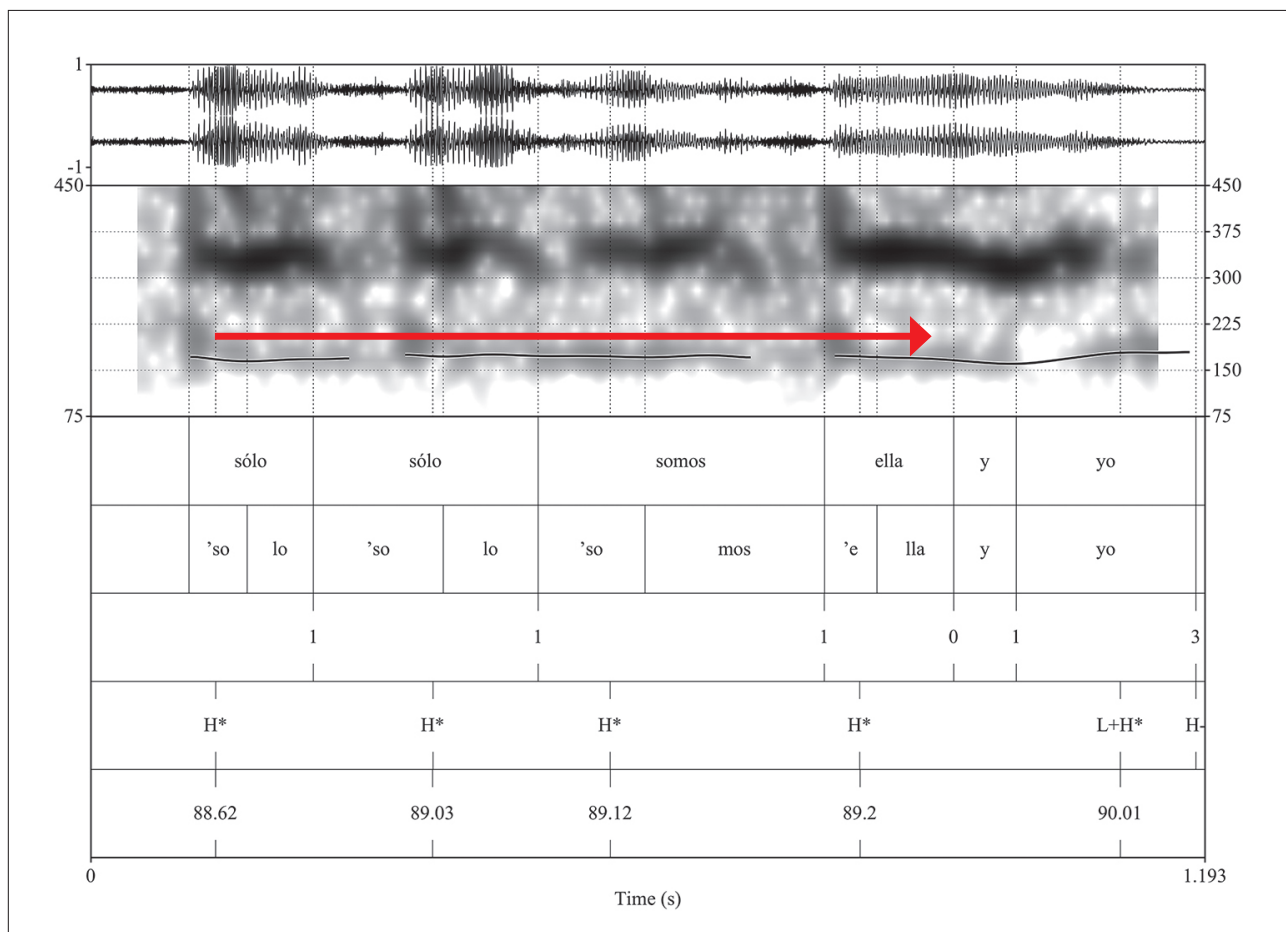

Fuente: CHDM, hombre, generación 1, nivel de instrucción 3.

I: mi hermana tiene veintisiete / pero mi hermana / tiene ya / pues más de cinco años / entre cinco y diez años no recuerdo bien / que no vive con nosotros / porque / este / primero se fue / creo que en el dos mil / se fue a hacer / se fue a hacer ella un // una / una maestría / a / no no es cierto no se fue a una maestría / se fue de intercambio / a / a Canadá $[\ldots]$

I: y bueno de / de mis hermanos / sólo/ sólo somos ella y yo / le digo / este

E: y / ¿viene frecuentemente o / bueno / está muy lejos ¿no? / pero / ¿qué tan / que / cada cuando viene / los visita? 
Figura 2. Una solamente tiene la primaria?

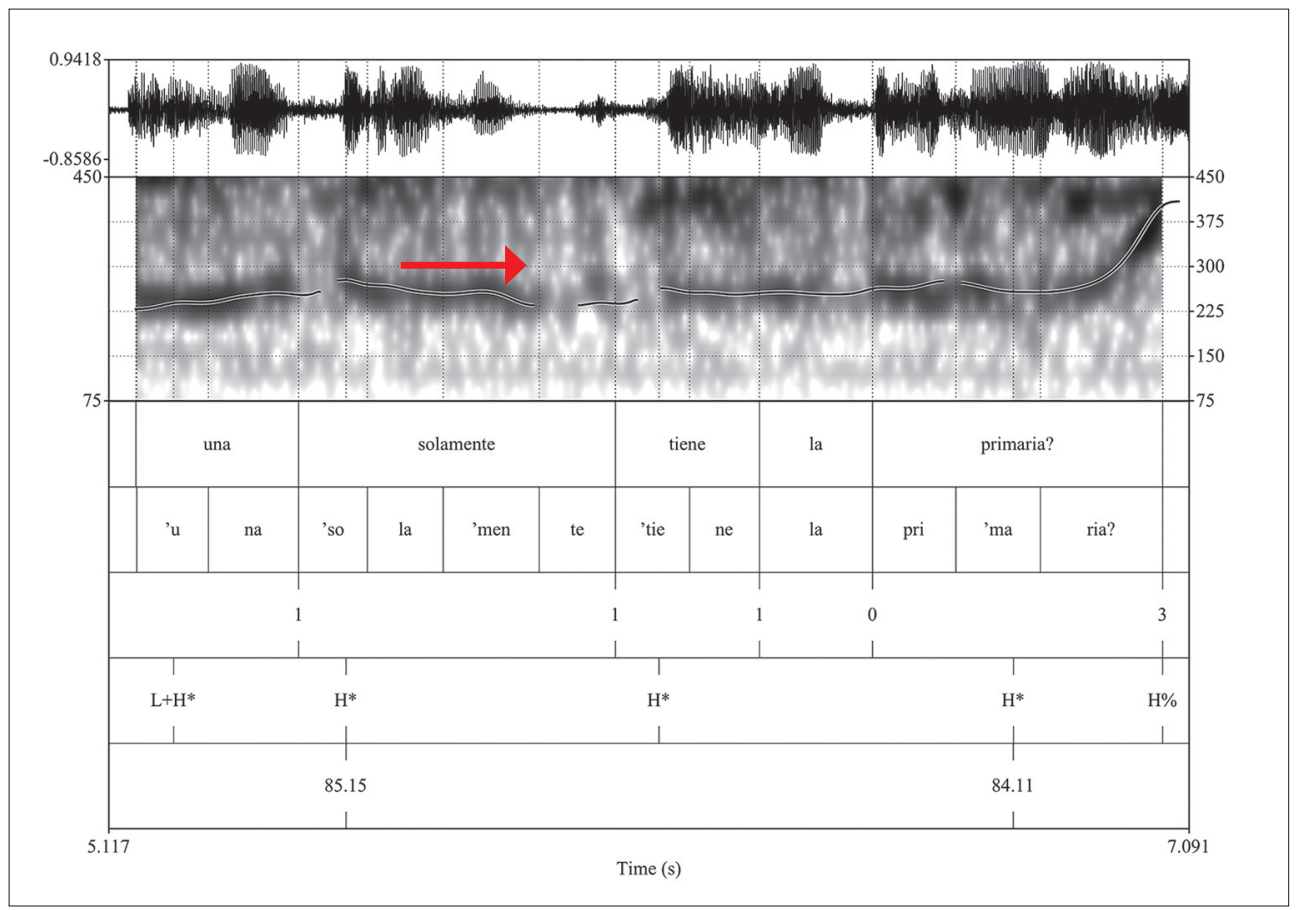

Fuente: CHDM, mujer, generación 1, nivel de instrucción 2.

\section{E: ¡él / aparte del español habla otro idioma? \\ E: sus hijas/ ellas solamente el español ¿verdad? \\ I: sí}

E: ¿una solamente tiene la primaria?

I: sí

En relación con el tono $\mathrm{L}+\mathrm{H}^{*}$, el operador corto presenta 15 ocurrencias, mientras que el operador largo cuenta con 13 realizaciones (Ver Tabla 1). El mayor ascenso tonal en esta configuración se presenta en la sílaba post-tónica, como se muestra en la Figura 3 con o sin desplazamiento del pico. Con frecuencia, este contorno ocurre cuando el adverbio encabeza un enunciado o cuando constituye por sí mismo una frase intermedia. El patrón melódico de ascenso ocurre, por lo regular, con focos amplios; en este grupo de datos, la presencia de este foco corresponde al $78 \%$. 
Figura 3. Sólo por ir a lavar un carro

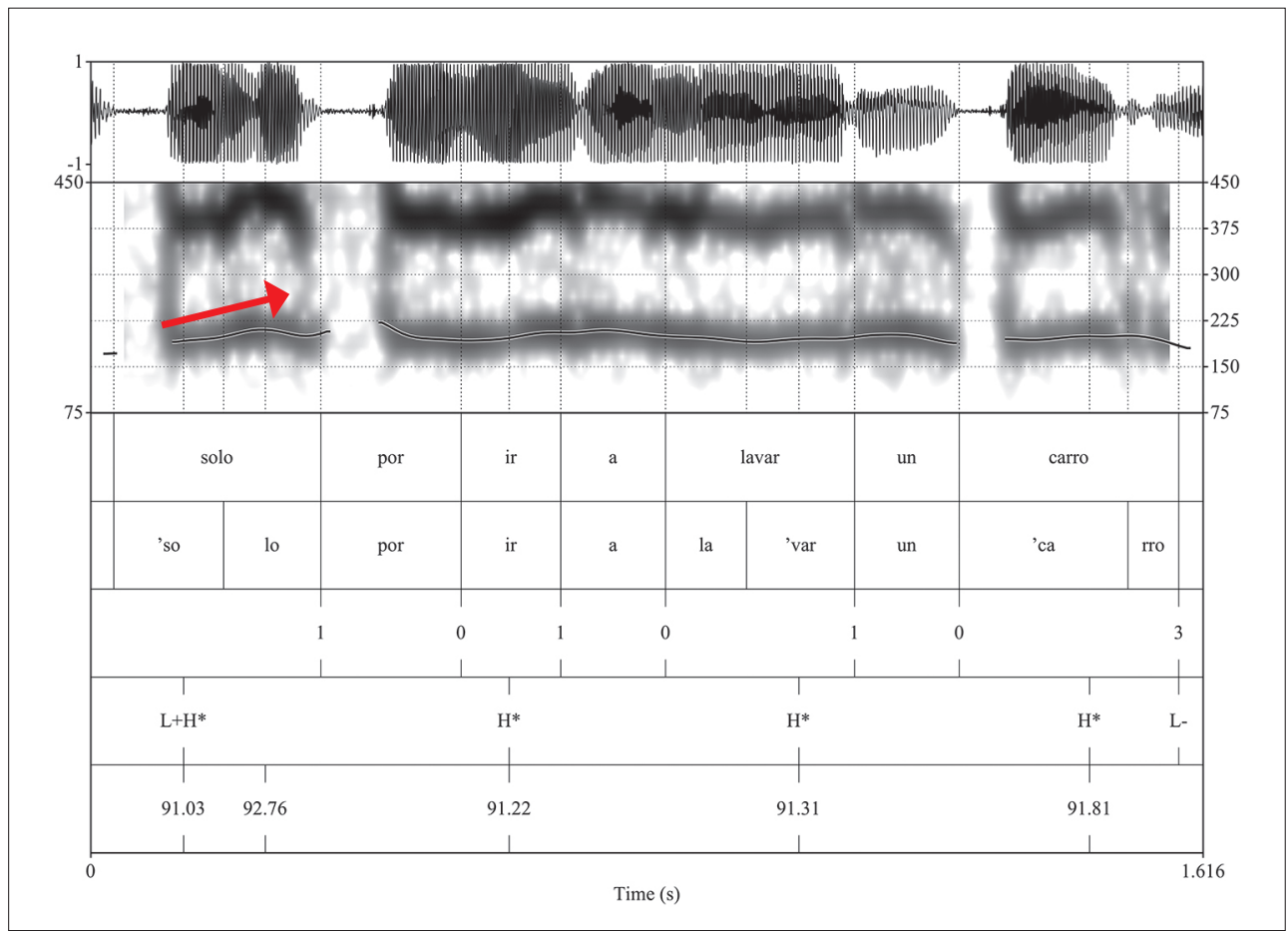

Fuente: CHDM, hombre, generación 1, nivel de instrucción 1.

E: ¿y por qué no te vas tú por ejemplo al rancho de allá donde dices que está bien chido y que comen muy bien? / ¿por qué prefieres estar aquí en Monterrey?

I: no pos este / sí he pensado irme de aquí porque sí no me agrada nada

I: aquí vivir pos si/ sólo por ir a lavar un carro / orita te ven/y jeh! como es oficial llega y te dice ¡eh! ¡tienes credencial? de permiso

E: permiso

I: jachis! No / pos no / pues lléguele de aquí 
Figura 4. Solamente por la Universidad Autónoma de Nuevo León

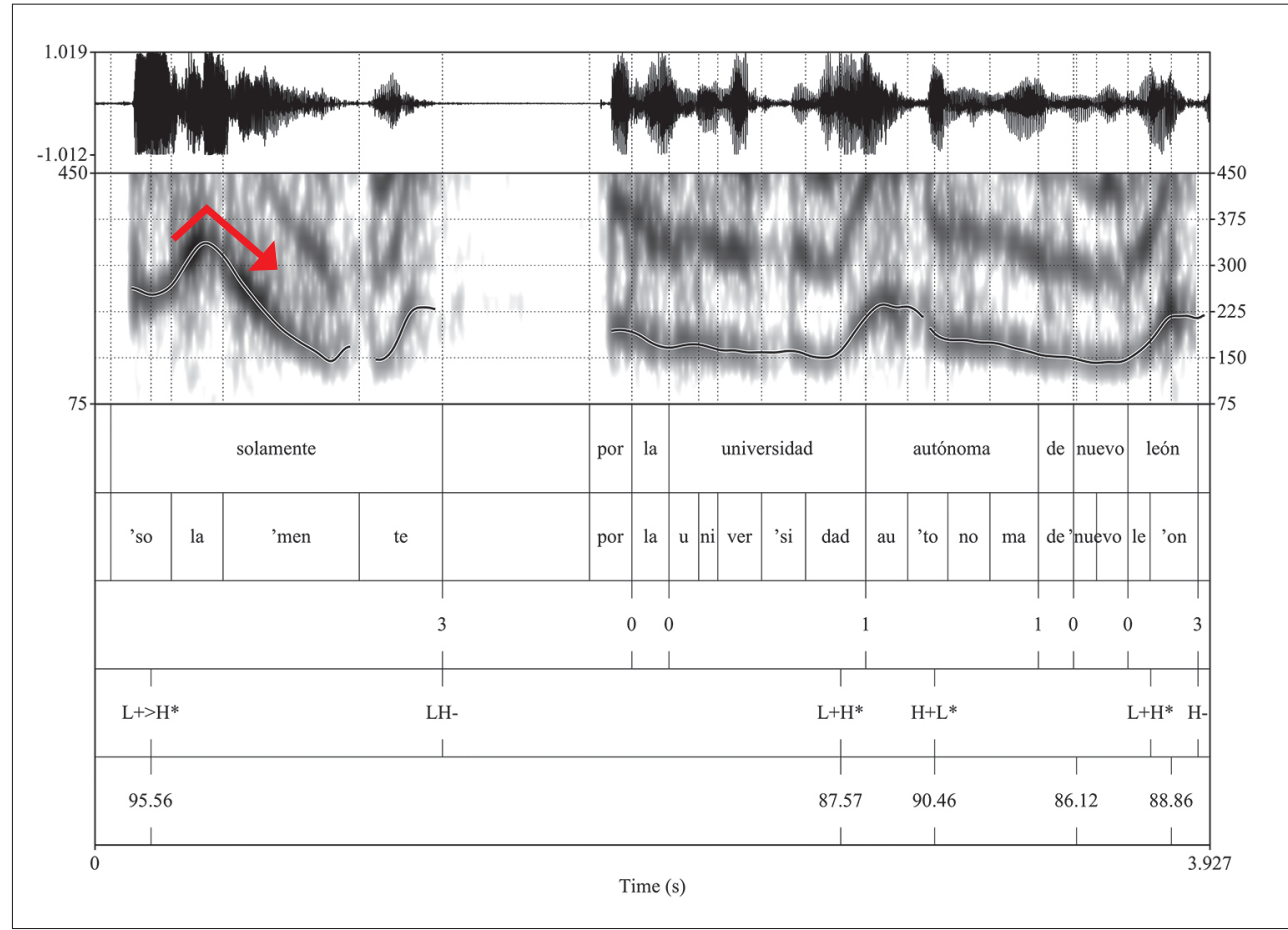

Fuente: CHDM, mujer, generación 1, nivel de instrucción 3.

I: sí / y te lo juro que yo como abogada / porque te conozco a ti la firmo / pero no la firmo / si tú / si no fueras tú

E: pero se te hace que / que hace falta que sea más explícita

I: y más a como están las cosas / o sea / este / que pueden ser utilizados / solamente /por la Universidad Autónoma de Nuevo León/ y para fines educativos / no para fines de que me hablen para ofrecerme una maestría

Por último, en la configuración $\mathrm{H}_{+} \mathrm{L}^{*}$, el foco amplio que representa el $56 \%$ de este tono no es tan definida como en los contornos anteriores. Se amplía el uso del patrón descendente a focos estrechos (44\%) y parece estar condicionado por un ascenso subsiguiente ligado a la información enfatizada. El operador presenta el descenso que contrasta con el realce melódico del foco, como se aprecia en la Figura 5. 
Figura 5. La calibración solamente contempla que lo verifiques

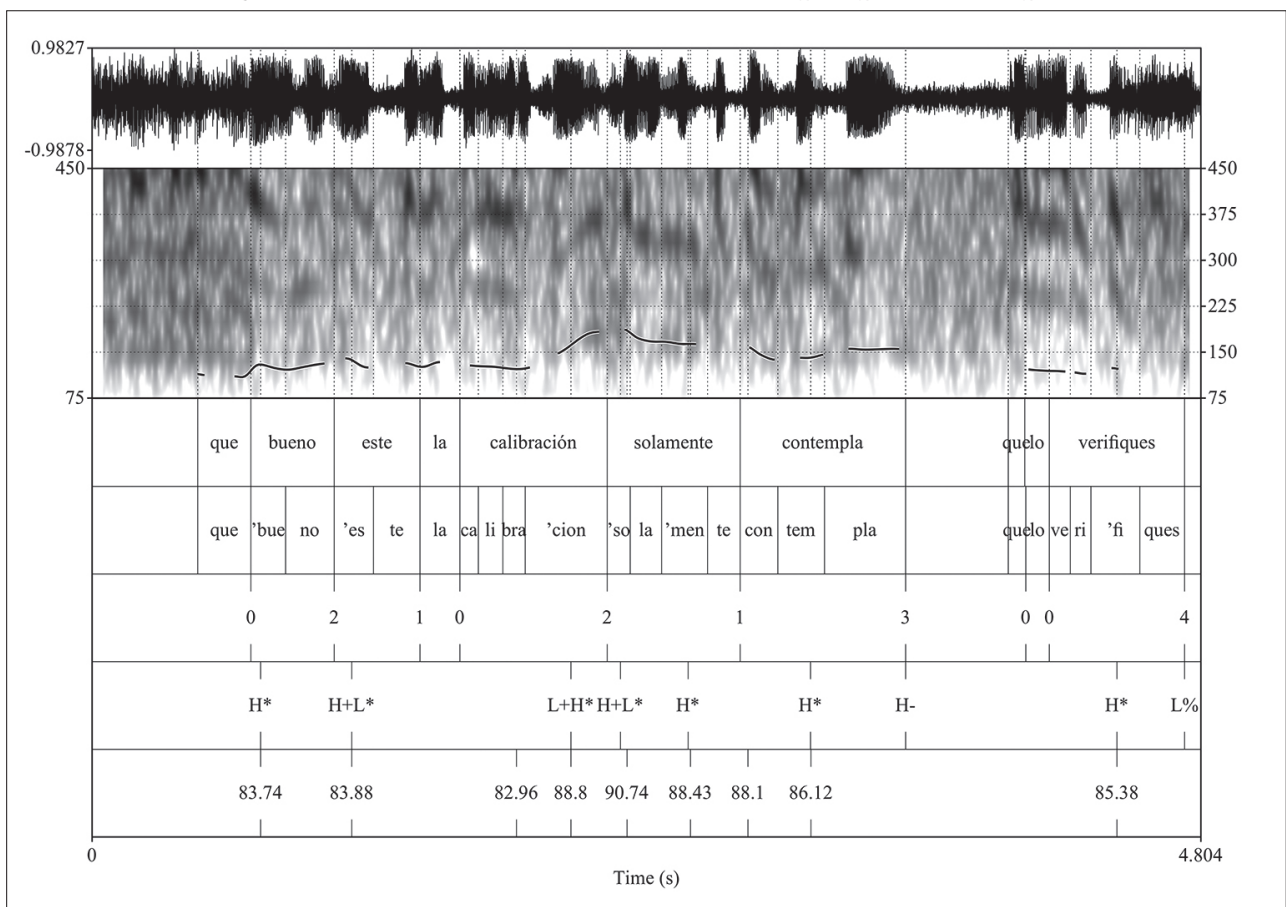

Fuente: CHDM, hombre, generación 1, nivel de instrucción 2.

I: pues eso se llama calibrar / es confirmar qué tan bien / o mal / mide tu instrumento

E: y si por ejemplo hay una diferencia en uno ¿cómo lo arreglas? / ¿o qué / qué es lo que hacen?

I: bueno / este / la calibración solamente contempla / que lo verifiques / tú nada más dices // tengo / este porcentaje de incertidumbre / y / ya / posteriormente a la calibración viene el ajuste

En general, la configuración prosódica de ambos adverbios es contrastiva. Por un lado, los tonos ascendentes y descendentes son característicos de los operadores cortos; y por el otro, la configuración alta-plana es preferida en los largos.

En cuanto al foco, los tres contornos aparecen mayoritariamente con amplio, es probable que este comportamiento se deba a las características inherentes del operador, pues su función básica de focalizador sugiere una proyección focal hacia toda la frase enunciativa a diferencia de lo que sucede con el foco estrecho; además, es probable que el tipo de instrumento de donde se extrajeron los ejemplos motive la presencia del foco amplio, pues en su mayoría son conversaciones entre desconocidos, así se presupone que la información nueva es dominante. 
Estos hallazgos revelan que el tipo de foco al que acompaña, amplio o estrecho, no condicionan el tipo de contorno melódico que surge en su empleo. Lo anterior sugiere que la aparición de una realización prosódica particular puede estar determinada por otros factores, entre ellos la información semántica o pragmática como se discutirá en adelante.

\subsection{Variación prosódica desde el punto de vista semántico-pragmático}

\section{Análisis semántico}

Para la clasificación semántica se consideraron tres valores básicos: exclusividad, unicidad y grado. Como se ha señalado previamente, el valor de exclusividad denota exclusión, límite o restricción (Seco, 2002, p. 417; Martínez, 2006, p. 1438; Ferrari, Giammatteo \& Albano, 2011, p. 30; Lara, 2011, p. 1524; Hummel, 2012, p. 143); esto es, cuando se deja fuera de un conjunto (expreso o tácito) la entidad denotada por el operador de foco (ASALE y RAE, 2010, p. 764) (ejemplificado en 8, Figura 1). ${ }^{15}$

8. I: mi hermana tiene veintisiete / pero mi hermana / tiene ya / pues más de cinco años / entre cinco y diez años no recuerdo bien / que no vive con nosotros / porque / este / primero se fue / creo que en el dos mil / se fue a hacer / se fue a hacer ella un // una / una maestría / a / no no es cierto no se fue a una maestría / se fue de intercambio / a / a Canadá [...]

I: y bueno de / de mis hermanos / sólo somos ella y yo / le digo / este

E: y / ¿viene frecuentemente o / bueno / está muy lejos ¿no? / pero / ¿qué tan / que / cada cuando viene / los visita?

Fuente: CHDM, hombre, generación 1, nivel de instrucción 3.

(Las entidades ella y yo se excluyen de un grupo mayor, en este caso hermanos)

Cuando se actualiza el valor semántico de unicidad, se alude al elemento focalizado como el único dentro del universo del discurso, como se muestra en (9) (García Fajardo, 2009).

9. E: ¡ajá! / por ejemplo / ¿cómo se siembra una palmera?

I: se le hace el / el pozo y luego ya / se mete

E: mjm / pero el ¿qué tan profundo debe hacer el pozo?

I: no pos depende / depende también como esté [...]

15 Se enmarca con negrilla la frase o cláusula que identifica el valor semántico. Además, para facilitar al lector la fluidez se reenumeran los ejemplos repetidos. 
I: el / la tierra / está / a veces / a veces hay / hay lugares que hay / hay piedras y todo eso $\mathrm{y} / \mathrm{a}$ veces se batalla $[\ldots]$

E: ¿por qué? / ¿por las piedras?

I: por las piedras

E: mjm

I: porque le estorban y / y no la deja / que se / que se meta más a la / sí a las raíces así

E: sí / en / entonces ¿cómo debes tú? / por ejemplo / fijarte que no haya piedras / ¿cómo le haces?

I: no pos/solamente escarbando el pozo y / y ya / ya así ves la / las piedras y / a quitarlas

Fuente: CHDM, hombre, generación 1, nivel de instrucción 1.

(No hay otra forma de quitar las piedras, es la única opción posible)

En cuanto al grado, se observa que estos operadores portan un valor cuantificacional que presupone una valoración gradual del elemento focalizado, de modo que lo elegido se encuentra, por lo regular, en menor grado en contraste con las opciones excluidas (Laguna y De Miguel, 1994, p. 104; Ferrari et al., 2011, p. 34) (Véase ejemplo 10, Figura 1).

10. I: y me voy a la / a tientas a la escalera y ca- / y había otros tratando de abrirla / y no podían por lo mismo / total entre todos la abrimos y caían / muros / y caían / vidrios / llovía así / aquí así caían caían caían / entonces queríamos salir / y pos no nos aniba- / animábamos

E: mjm

I: porque / moviéndose todo y cayendo / escombro

$\mathrm{E}:$ ¿pedazos muy grandes?

I: muros completos / total ya le / se para / y este / y descanso obviamente / justo me puse un pantalón / y bajar la escalera / y como se había roto / y había quedado la escalera / pues a lo mejor a la altura de la / teja / no sé E: mjm I: pos había que saltar <risas = "I"/> / pos a saltar descalzo / sobre vidrios y escombro

E: jagh!

I: fortunadamente sólo me herí poquito en los pies

E: mjm 
I: con los vidrios / y ya me fui a / a Reforma / contemplar aquello ahí / pesado / tremendo / muertos y // y ahí tuve / ahí ahí sí la vi muy cerquita

E: ¿̨uánto tiempo estuvo ahí después del / del terremoto?

Fuente: CHDM, hombre, generación 3, nivel de instrucción 3.

(Las heridas en los pies fueron lo mínimo que le sucedió, dado que pudo haber perdido la vida)

El mayor número de usos de los operadores del foco coinciden con la lectura de unicidad, que representa el $45 \%$ de los datos. Por otro lado, los valores de exclusividad y de grado mostraron el mismo porcentaje de ocurrencias, $27 \%$ en cada caso (Véase Tabla 2). ${ }^{16}$

Tabla 2. Distribución semántica del par adverbial

\begin{tabular}{|l|c|c|c|}
\hline \multicolumn{4}{|c|}{ Distribución semántica global } \\
\hline \multicolumn{1}{|c|}{ Valor } & Sólo & Solamente & Total \\
\hline Unicidad & $21(53 \%)$ & $19(48 \%)$ & $40(45 \%)$ \\
\hline Exclusión & $9(38 \%)$ & $15(63 \%)$ & $24(27 \%)$ \\
\hline Grado & $15(63 \%)$ & $9(38 \%)$ & $24(27 \%)$ \\
\hline Total & $45(51 \%)$ & $43(49 \%)$ & $88(100 \%)$ \\
\hline
\end{tabular}

En relación con la configuración melódica, se encontró que no hay una tendencia asociada a cada uno de los valores semánticos, en términos generales puede observarse en la Tabla 3 que la curva melódica de mayor frecuencia es alta-plana en los tres grupos.

Tabla 3. Distribución semántica configuración del par adverbial

\begin{tabular}{|l|l|c|}
\hline \multicolumn{3}{|c|}{ Distribución semántica configuracional } \\
\hline \multirow{2}{*}{ Valor } & \multicolumn{1}{|c|}{ Configuración } & Total \\
\hline \multirow{2}{*}{ Unicidad } & alta-plana & 22 \\
\cline { 2 - 3 } & descendente - ascendente & 18 \\
\hline \multirow{2}{*}{ Exclusión } & alta-plana & 12 \\
\cline { 2 - 3 } & descendente - ascendente & 12 \\
\hline \multirow{2}{*}{ Grado } & alta-plana & 13 \\
\cline { 2 - 3 } & descendente - ascendente & 11 \\
\hline & \multicolumn{2}{|c}{ Total } \\
\hline
\end{tabular}

16 Los porcentajes medios están en función de su representación por grupo. Los porcentajes periféricos muestran la tendencia de acuerdo con el conjunto de los 88 ejemplos. 


\section{Análisis pragmático}

El significado pragmático que proporcionan estos operadores de foco es el de matizador: ${ }^{17}$ dentro de este valor, se distinguen tres tipos: matización que atenúa, matización que intensifica y matización cero. Con el primero, el hablante busca minimizar o restar importancia a la información focalizada; con el segundo, se pondera lo dicho; y con el tercero prevalece el significado de exclusión sin valoraciones adicionales (Obsérvense 11, 12 y 13 respectivamente). ${ }^{18}$

11. I: pos había que saltar <risas = "I"/> / pos a saltar descalzo / sobre vidrios y escombro

E: jagh!

\section{I: fortunadamente sólo me herí poquito en los pies (CHDM)}

Fuente: CHDM, hombre, generación 3, nivel de instrucción 3

(El emisor resta valor o importancia al daño).

12. E: pos no / la única que conozco le digo es / Nuevo Laredo / y nada más / pero igual tampoco he cruzado para allá para / Estados Unidos // siempre he estado / acá /en México / è las costumbres / cómo son / en / no sé / en una celebración de navidad en Reynosa y / de aquí de Monterrey? / ¿varía mucho?

I: son parecidas / acuérdate que // como decía Vasconcelos / que a mi comadre Lidia le // le clavó una espina en el corazón / donde empieza la carne asada se acabó la cultura < risas = "E" / > // nunca me le he perdonado / una vez que los invité a cenar a tu casa / y di pulpos / de diez gentes / solamente dos / comieron los pulpos los demás me lo dejaron / entre ellos mi comadre / ¡inculta analfabeta no te puedo decir porque sí sabes leer $<$ risas = "todos" $/>$ / ahora ya dice que ya come / pulpos y demás ¿̇no? / pero / e / aquí la gente es carnívora / cien por ciento carnívora ¿sí? / e / yo soy del puerto así que es otro tipo de comida / pescados / mariscos / cerdo / carne y demás / hay muy buena carne aquí

Fuente: CHDM, hombre, generación 3, nivel de instrucción 3.

(El emisor intensifica para resaltar la información).

17 Entendemos el concepto de matizador como una estrategia prosódica para indicar fuerza ilocutiva que ayuda al hablante a dar información no explícita en la emisión linguística, sino implicada por el contexto.

18 Se enmarca con negrilla la información contextual discursiva que permite entender el valor matizador. 
13. E: ¡ajá! / por ejemplo / ¿cómo se siembra una palmera?

I: se le hace el / el pozo y luego ya / se mete [...]

E: [...] ¿cómo se siembra una palmera? [...] ¿Cómo debes tú? / por ejemplo / fijarte que no haya piedras / ¿cómo le haces?

I: no pos/ solamente escarbando el pozo y / y ya / ya así ves la / las piedras y / a quitarlas

Fuente: CHDM, hombre, generación 1, nivel de instrucción 1

(No hay otra forma de quitar las piedras, es la única opción posible)

La distribución pragmática del par adverbial muestra que, en total, 38 operadores de foco portan valor matización cero lo que equivale al 43\% de los datos, 27 operadores tienen el valor atenuador (31\%) y los 23 restantes tienen valor intensificador (26\%), como se muestra en la Tabla 4.

Tabla 4. Distribución pragmática del par adverbial

\begin{tabular}{|l|c|c|c|}
\hline \multicolumn{5}{c|}{ Distribución pragmática global } \\
\hline \multicolumn{1}{|c|}{ Valor } & Sólo & Solamente & Total \\
\hline Cero & $17(45 \%)$ & $21(55 \%)$ & $38(43 \%)$ \\
\hline Atenuador & $16(59 \%)$ & $11(41 \%)$ & $27(31 \%)$ \\
\hline Intensificador & $12(52 \%)$ & $11(48 \%)$ & $23(26 \%)$ \\
\hline Total & $45(51 \%)$ & $43(49 \%)$ & $88(100 \%)$ \\
\hline
\end{tabular}

En términos prosódicos, se observa que los valores pragmáticos presentan correlación con la realización melódica (Véase Tabla 5 abajo). Cuando se expresa atenuación, la curva melódica del operador de foco se dibuja ascendente y el contorno del foco se dibuja descendente, lo que supone que el hablante hace énfasis en el operador de foco y se debilita en el foco para incitar la lectura de atenuación, como en la Figura 6. 
Figura 6. Sólo me herí poquito en los pies (Ver ejemplo 10)

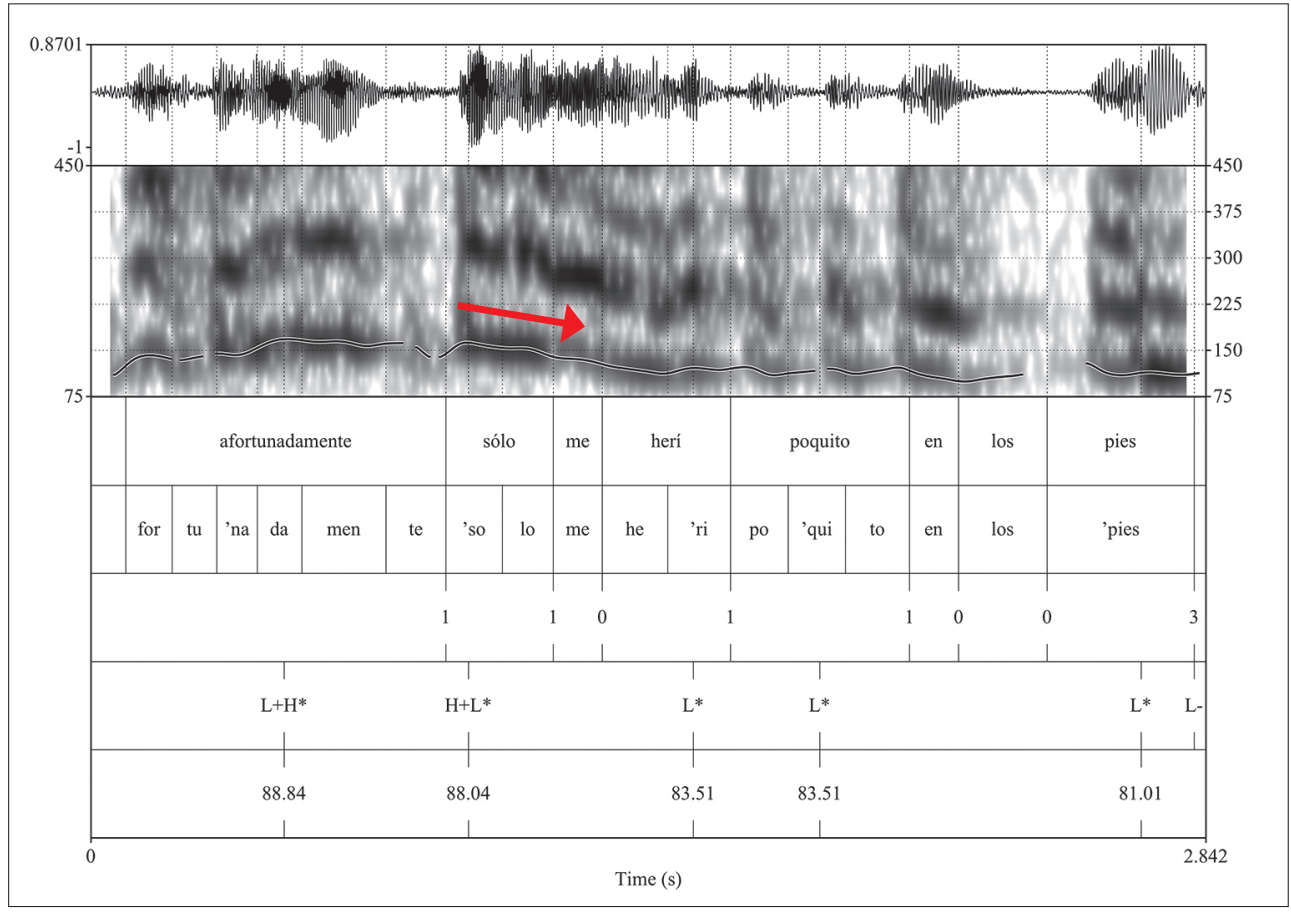

Fuente: CHDM, hombre, generación 3, nivel de instrucción 3.

Por otro lado, cuando se expresa intensificación, la configuración va acompañada de un movimiento descendente en el operador de foco para ascender luego en el foco. El hablante imprime un realce melódico al elemento focalizado en contraste con el descenso previo, esto implica que el hablante baja el tono en el focalizador para ascender en el elemento focalizado como evidencia de matización (Figura 7). 
Figura 7. Solamente/ dos/ comieron los pulpos (ver ejemplo 14)

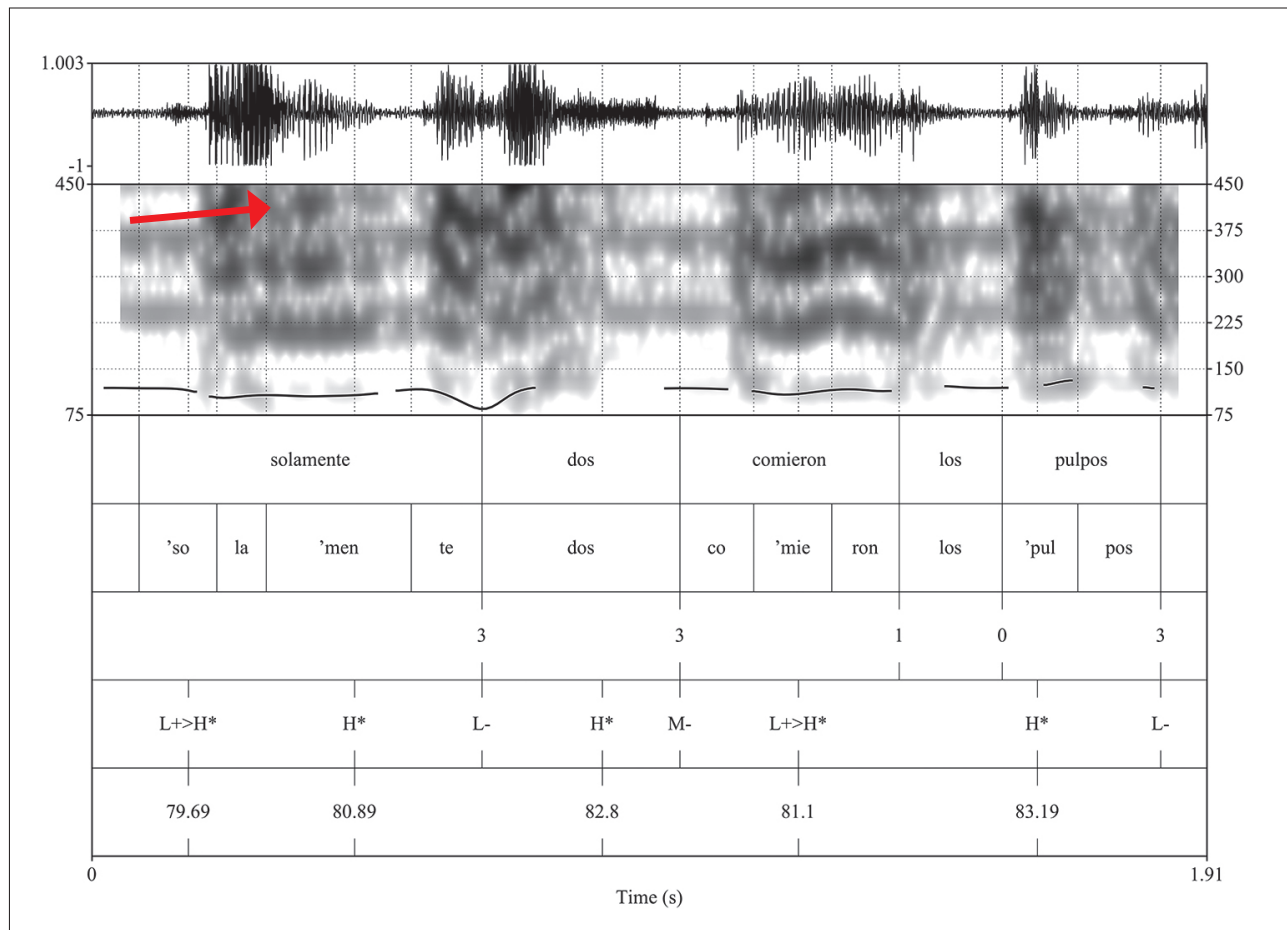

Fuente: CHDM, hombre, generación 3, nivel de instrucción 3.

Por último, cuando la enunciación carece de matización (matización cero) el contorno melódico transcurre de manera alta- plana como en Figura 1 y 2.

Tabla 5. Distribución pragmática configuracional

\begin{tabular}{|l|l|c|}
\hline \multicolumn{3}{|c|}{ Distribución pragmática configuracional } \\
\hline \multirow{4}{*}{ Valor } & \multicolumn{1}{|c|}{ Configuración } & Total \\
\hline \multirow{4}{*}{ Cero } & alta-plana & 32 \\
\cline { 2 - 3 } & ascendente & 4 \\
\cline { 2 - 3 } & descendente & 2 \\
\hline \multirow{3}{*}{ Atenuador } & alta-plana & 11 \\
\cline { 2 - 3 } & ascendente & 10 \\
\cline { 2 - 3 } & descendente & 6 \\
\hline & alta-plana & 4 \\
\cline { 2 - 3 } & ascendente & 4 \\
\cline { 2 - 3 } & descendente & $\mathbf{8 8}$ \\
\hline
\end{tabular}


Hasta este punto, la curva melódica presenta una tendencia clara cuando se expresa atenuación o intensificación, pero no se trata de una categoría discreta, dado que hay casos en los que se observa que la matización se apoya en otras estrategias discursivas como el contexto o el contenido léxico,${ }^{19}$ no necesariamente en la realización prosódica (Ver Figura $8)$.

Figura 8. El carro no estaba golpeado de adelante, solamente de atrás

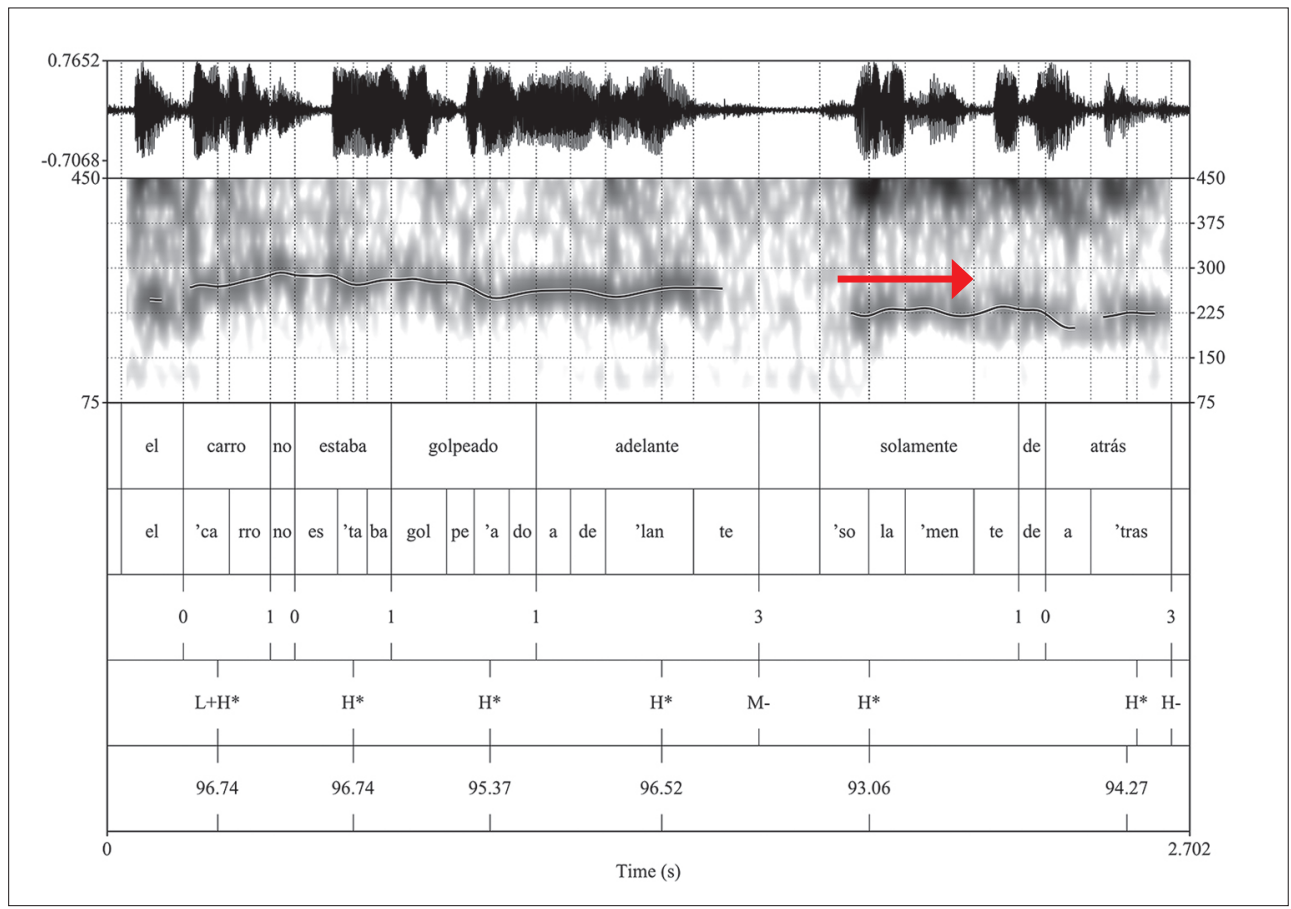

Fuente: CHDM, mujer, generación 2, nivel de instrucción 2.

I: a esas horas me fui yo sola / entonces este / me fui / y yo iba pensando / como soy diabética / yo dije jay no! dije / ¡diosito santo ayúdame! / ¡ayúdame señor dame fuerzas! / yo se que lo voy a encontrar destrozado / sangrado / o sea sabrá dios / yo / no sé cómo lo voy a encontrar / pero dame muchas fuerzas señor / porque voy sola / y y no ten- / o sea no tengo quien me dé la mano más que tú

19 En el contexto discursivo, se observan indicadores de la fuerza ilocutiva como el léxico: interjecciones jachis!, jórale!, iay!, ¡agh!, ¡hijo!, ¡chin!, ¡bah!, ¡hijole!; e intensificadores tan, y ya, muy, pura, pinche, chingado. Asimismo, aparecen estrategias argumentativas como la ejemplificación y la enumeración, que permiten implicar el significado pragmático, para este último véase Figura 8. 

E: mjm
I: tú me vas a ayudar y tú me vas a sacar adelante
E: claro
I: y ahí voy yo / pídele y pídele a dios / llegué me estacioné / vi el carro / el carro no estaba golpeado de adelante / solamente de atrás / la / la cajuela estaba así de en medio / como / con el poste
E: partida

\section{Conclusiones}

El par adverbial sólo-solamente no presenta configuraciones que indican tendencias vinculadas a la extensión silábica del adverbio. Los movimientos melódicos asociados con los operadores de foco son alto-plano, ascendente y descendente. El tono alto-plano resultó ser el más común en los datos, y no se muestra condicionado por la información semántica (Véase Tabla 3); sin embargo, esta configuración se asocia mayoritariamente con el valor de unicidad, mientras que en el valor de grado se presenta mayor variabilidad prosódica. En contraste, la distribución melódica de acuerdo con el valor pragmático muestra correlaciones más consistentes. Un movimiento ascendente en el operador seguido por un descenso en el foco permiten mostrar la atenuación del contenido enunciado, y un movimiento descendente en el operador más un contorno ascendente en el foco reflejan intensificación. Sin embargo, la variación prosódica como indicador de la fuerza ilocutiva no es el único recurso empleado por los hablantes para matizar la información, pues la presencia de elementos léxicos puede ser suficiente para promover la intención. En este sentido, habría que hacer una investigación dirigida exclusivamente a reconocer cuáles son los cotextos y contextos que favorecen el uso de estrategias prosódicas para atenuar e intensificar la información en datos de habla espontánea. No obstante, resulta claro que la prosodia del par adverbial es de naturaleza variable y que parece estar fuertemente condicionada por factores de tipo pragmático. 


\section{Referencias bibliográficas}

Albelda, M. (2002). La intensificación pragmática y su reflejo a través de la prosodia. Actas del V Congreso de Lingüística General. M. Villayandre (ed.). Madrid: Arco Libros, pp.199-210.

Arjona Iglesias, M. (1991). Estudios sintácticos sobre el habla popular mexicana. México: UNAM.

Boersma, P., y Weenink, D. (2013). PRAAT version 5.3.42. Doing phonetics by computer. Institute of Phonetic Sciences, Univ. of Amsterdam. Recuperado el 10 de julio del 2014, de http:// www.fon.hum.uva.nl/praat/

De Mello, G. (1992). Adjetivos adverbializados en el español culto hablado de diez ciudades. Lingüística del español actual, 14, 225-242.

Di Tullio, Á. (2010). Manual de gramática del español. Buenos Aires: Waldhuter.

Egea, R. E. (1979). Los adverbios terminados en -mente en el español contemporáneo. Bogotá: Publicaciones del Instituto Caro y Cuervo.

Estebas Vilaplana, E., y Prieto, P. (2008). La entonación prosódica del español: Una revisión del Sp_ToBI. Universidad Nacional de Educación a Distancia, pp. 263-283.

Face, L. T. (2002). El foco y la altura tonal en español. Boletín de Lingüística, 17, 30-52. Universidad de Minnesota.

Ferrari, L., Giammatteo, M. y Albano, H. (2011). Operadores de foco: el caso de incluso, hasta, solo y aun. Cuadernos de la ALFAL, 3, 30-41. Recuperado el 21 de marzo de 2014, de http://mundoalfal.org/sites/default/files/revista/03_cuaderno_005.pdf

García Fajardo, J. (2009). Semántica de la oración. Instrumentos para su análisis. México: El Colegio de México.

Gutiérrez Bravo, R. (2008). La identificación de los tópicos y los focos. Nueva Revista de Filología Hispánica, 56(2), 363-401.

Gutiérrez, Y. M. (2010). Sobre foco nomás. En V. M. Castel y L. Cubo de Severino (eds.) La renovación de la palabra en el bicentenario de la Argentina. Los colores de la mirada lingüística. pp. 625-632.

Hoeksema, J., y Zwarts, F. (1991). Some remarks on Focus adverbs. Journal of Semantics, 8, 5170. University of Groningen.

Hualde, J. I. (2003). El modelo métrico autosegmental. En: P. Prieto (ed.). Teorías de la entonación. (pp. 155-184). Barcelona: Ariel. 
Hummel, M. (2002). Sincronía y diacronía del sistema atributivo de las lenguas románicas. Revista Lengua. Revista especializada en lingüística y ciencias de lenguaje, 13, 9-48.

Hummel, M. (2012). Polifuncionalidad, polisemia y estrategia retórica. Los signos discursivos con base atributiva entre oralidad y escritura, Acerca de esp. Bueno, claro, total, realmente, etc. Berlin: Gruyter, pp. 142-269.

Kaul de Marlangeon, S. B. (2002). Los adverbios en -mente del español de boy y su función semántica de cuantificación. Madrid: Vervuert.

Kovacci, 0. (2000). El adverbio. En I. Bosque y V. Demonte (eds.). Gramática descriptiva de la lengua española 1, Sintaxis básica de las clases de palabras. Madrid: Espasa, pp. 705-786.

Lara Ramos, L. F. (2011). Diccionario del español de México. México: El Colegio de México.

Lastra, Y., y Butragueño, P. M. (2000). El modo de vida como factor sociolingüístico en la ciudad de México. México: El Colegio de México.

Lastra, Y., y Butragueño, P. M. (2003). Metodología del "proyecto para el estudio sociolingüístico del español de España y de América”. México: El Colegio de México.

Lastra, Y., y Butragueño, P. M. (2009). "Corpus sociolingüístico de la ciudad de México” Materiales de PRESEEA - MÉXICO. México: El Colegio de México.

Lope Blanch, M. J. (1977). Operadores pragmáticos de actitud oracional: los adverbios en mente, en Estudios sobre el español hablado en las principales ciudades de América. México: UNAM, pp. 313-332.

Martínez Marín, J. (2006). Los adverbios en -mente y los diccionarios modernos del español: perspectiva pragmático-discursiva, en Análisis del discurso: lengua, cultura, valores: Actas del I Congreso Internacional / coord. por Manuel Casado Velarde, Ramón González Ruiz, María Victoria Romero Gualda, Vol. 2. Madrid: Arco Libros, pp. 1433-1444.

Mora, B. A. (2011). Variación y cambio fonético. Adverbios y prosodia. México: UAM, pp. 123145 .

Pamies, A., Fernández Planas, A. M., Martínez Celdrán, E., Ortega Escandel, A., y Amorós, M. C. (2002). Umbrales tonales en español peninsular. En: II Congreso Nacional de Fonética Experimental. Díaz García, J. (ed). Sevilla: Universidad de Sevilla, pp. 272-278.

Prieto, P. (2003). Teorías de la entonación. Barcelona: Ariel.

Real Academia Española. (2010). Madrid: Espasa.

Rodríguez, A. L., Flores, M. E., y Pérez, T. (2012). Corpus Monterrey-PRESEEA. México: UANL. 
Seco, M. (2002). Diccionario de dudas y dificultades de la lengua española. Madrid: Espasa.

Sosa, J. M. (2003). La notación prosódica en español. Una revisión del Sp-ToBI. En: P. Prieto (ed.). Teorías de la entonación. Barcelona: Ariel, pp. 263-283.

Vigueras, A. (1983). Sintaxis de los adverbios en -mente en el habla culta de la ciudad de México. En: Anuario de letras XXI. Facultad de filosofía y letras y centro de lingüística hispánica del instituto de investigaciones filológicas. México: UNAM.

Zubizarreta, Ma . L. (2000). Las funciones informativas: Tema y foco. En: I. Bosque \& V. Demonte (eds.). Gramática descriptiva de la lengua española 3, pp. 4217-4243. Madrid: Espasa. 